\title{
Dietary nucleotides and gut mucosal defence
}

\author{
G K Grimble
}

\begin{abstract}
The informational aspects of nucleic acid synthesis have attracted much more attention than the quantitative significance of DNA, rRNA, tRNA, and nucleotide synthesis. Animal and human studies suggest that in energetic terms, $5-10 \%$ of the energy used in synthesising tissue protein is expended in manufacturing an appropriate amount of synthetic machinery, that is the ribosome and tRNA. The two sources for synthesis of nucleotides are salvage of nucleotides released by intracellular degradation or derived from the diet, and nucleotides synthesised de novo from amino acids (for example, glutamine) and sugars (glucose). The comparative importance of these two processes is not well defined, but rRNA production requires a high de novo input in cell types with the capacity for rapid division (for example, lymphocytes). The gut is unusual in requiring a ready arterial supply of nucleotides synthesised by hepatic de novo pathways. Animal studies show that an exogenous supply of nucleotides (salvage) can improve liver regrowth, immune responsiveness to a microbial challenge, and gut morphology in diarrhoea models. Humans adapt to dietary nucleotide intake by downregulating de novo pathways. All total parental nutrition regimens, and most enteral regimens lack nucleotides, which may predispose to an inadequate supply of preformed nucleotides to gut and immune cells in the critically ill,
\end{abstract}

Aspartic acid

Nutrition, Central Middlesex Hospital, London G K Grimble

Correspondence to: Gastroenterology \& Nutrition, Central Middlesex Hospital, Acton Lane, London NW10 7NS. Dr G K Grimble,

artificially fed patient. Unfortunately, there are no clinical studies that answer this point at present.

(Gut 1994; supplement 1: S46-S51)

Nucleic acids are not thought to be essential nutrients as pathways exist for synthesis of purines and pyrimidines, de novo. Most recent basic nucleic acid research has concentrated on the 'informational' aspects, rather than 'metabolic' aspects of their metabolism. Examples would include modulation of cytokine mRNA concentrations ${ }^{1}$ or muscle ribosome concentrations as mediators of posttraumatic changes in protein synthesis. ${ }^{2}$

This paper will define several factors related to dietary provision of nucleotides (Table). How are synthetic pathways for purine and pyrimidines affected by the dietary intake of purines and pyrimidines? What is the nature of purine and pyrimidine requirements and can endogenous purine and pyrimidine supply ever be exceeded by demand in the acutely ill patient? Will organ function be impaired by no intake of purines and pyrimidines as occurs for most patients fed with most current enteral and parenteral formulas?

\section{Pathways of purine and pyrimidine}

biosynthesis

Endogenous purines and pyrimidines are synthesised de novo, from amino acids and other small molecules. The two pathways differ in that the ribose moiety of purine nucleosides is incorporated as 5-phosphoribosyl-1-phosphate (PRPP) in the first reaction of purine synthesis, but for pyrimidines is incorporated at the end stage after the pyrimidine ring has been fully formed, as reviewed elsewhere. ${ }^{3-5}$

\section{SYNTHESIS}

Endogenous purines and pyrimidines are synthesised de novo, from amino acids and other small molecules (Fig 1). Pyrimidines are synthesised from $\mathrm{NH}_{3}, \mathrm{CO}_{2}$, and aspartate, the

Key aspects of dietary nucleotide metabolism in relation to gut mucosa

1 What are the pathways of synthesis of purines and pyrimidines?

2 Are they affected by dietary intake of purines and pyrimidines?

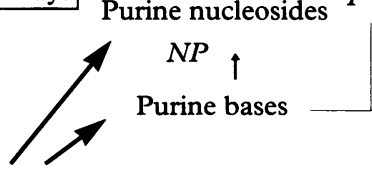

Pyrimidine bases igure 1: Pathways of purine and pyrimidine metabolism. The intracellular nucleotide precursor pool is maintained by de novo synthesis and salvage of purines and pyrimidines from dietary sources and from intracellular degradation of RNA and DNA. $P R T$ ase $=$ phosphoribosyltransferase,$N P=$ nucleoside phosphorylase, $N K=$ nucleoside kinase.

3 What is the nature of purine and pyrimidine requirements?

4 Is endogenous purine and pyrimidine supply ever exceeded by demand (for example, in acutely ill patients)?

5 Is organ function impaired by no intake of nucleotides (for example, all total parenteral nutrition and most enteral nutrition)? 


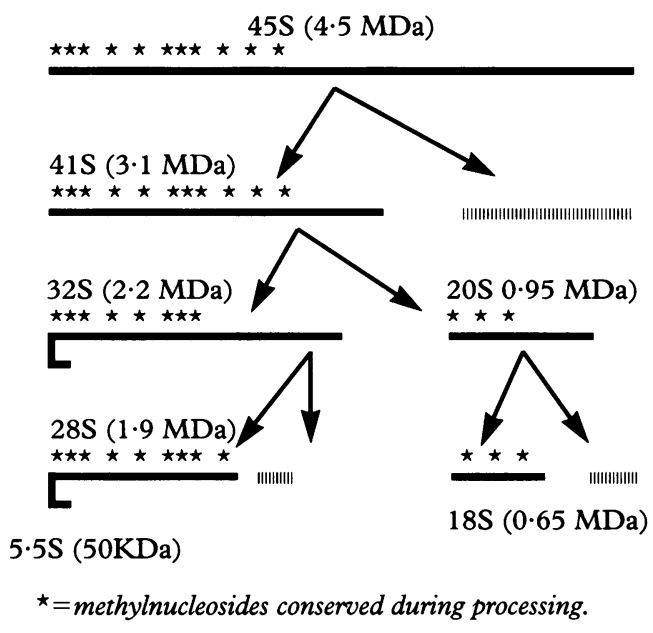

Figure 2: Nucleolar rRNA processing in mammalian cells.

latter being synthesised from glutamine in lymphocytes. ${ }^{6}$ The ribose and phosphate moieties are derived from glucose and ATP respectively. In contrast, purines incorporate the $\gamma-\mathrm{NH}_{2}$ group of glutamine (2), nitrogen from glycine and aspartate ( 1 or 2 ), and carbon from $\mathrm{CO}_{2}$ formate, glycine, and aspartate. The sugar and phosphate moieties are as for pyrimidines.

\section{SALVAGE AND CATABOLISM}

Degradation of the $5^{\prime}$ mono, di, and triphosphates occurs through the stepwise removal of phosphate and ribose (or 2' deoxyribose) to form the nucleobases, uracil, cytosine (pyrimidines) or hypoxanthine (purines). Salvage of the nucleobases occurs by a single step addition of PRPP to form the $5^{\prime}$ monophosphate (hypoxanthine-guanosine phosphoribosyl transferase (HGPRTase)) (see Fig 1).

\section{URINARY EXCRETION OF BREAKDOWN \\ PRODUCTS}

Degradation products of orotic acid, uracil, and cytosine include $\beta$-alanine and $\beta$-aminoisobutyric acid. Purine catabolism seems to be controlled by three factors, namely intracellular PRPP concentrations, the activity of the phosphoribosylamidotransferase (PRPP+ gln $->5^{\prime} P$ ribosylamine + glu), and the intracellular concentrations of IMP, AMP, and GMP. ${ }^{5}$ An adequate intracellular concentration of nucleotide monophosphates will inhibit the first step in purine synthesis, an adequate supply of the precursor PRPP, will activate it.

\section{Relation between salvage and de novo synthesis of purines and pyrimidines}

EVIDENCE FROM WHOLE ANIMAL STUDIES There is some incorporation of dietary purines and pyrimidines into tissue ribonucleic acid (RNA), DNA, and nucleotide pools ${ }^{3}$ and this represents the exogenous counterpart of the intracellular salvage pathways. The route of administration considerably affects urinary excretion of purines, the same oral dose being poorly incorporated in tissue nucleic acids, compared with intravenous administration. ${ }^{7}$ This may relate to the low capacity of intestinal transport mechanisms that exist for all four purine/pyrimidine bases ${ }^{8-10}$ as excess intake is fermented by colonic bacteria.

Savaiano et al $^{7}$ saw that those tissues most actively participating in nucleic acid synthesis had the highest incorporation ratio $\left({ }^{14} \mathrm{C}\right.$ intravenous: ${ }^{14} \mathrm{C}$ oral) and included salivary, adrenal, thyroid, thymus and pituitary glands, and lymph tissue (ratio 25-59), whereas it was only three for liver. Similar results have been obtained in rats infused with nucleoside/ nucleotide mixtures. ${ }^{11}$ Adenine could be taken up intact by the gut, whereas guanine, hypoxanthine, and xanthine were extensively catabolised in their passage from mucosa to serosa, implying that the gut has low capacity for de novo adenine synthesis. ${ }^{12}$ This would explain the different fate of oral or intravenous purines on the basis of the gut mucosa's high requirement for exogenous purines, which results in preferential extraction of luminal nucleotides during first pass through gut and liver. ${ }^{13}$

A reciprocal relation between purine intake and de novo synthesis exists in the gut ${ }^{1415}$ as urinary excretion of catabolites was reduced during dietary purine restriction. ${ }^{1617}$ Dietary supplementation with pyrimidines suppressed de novo synthesis in gut mucosa, suggesting that under normal circumstances, this pathway was comparatively inactive and could only be stimulated by omission of purines and pyrimidines from the diet. ${ }^{14} 15$ This relation, however, relies on an adequate dietary protein intake to supply substrate for de novo synthesis. ${ }^{18} 19$

EVIDENCE FROM CELL CULTURE STUDIES

The technique of measuring RNA synthesis in cultured cells is complicated by intracellular compartmentation of nucleotide pools. These can be labelled by $\left[{ }^{14} \mathrm{C}\right]$-uridine or $\left[{ }^{14} \mathrm{C}\right]$-orotic acid, which enter the salvage and de novo pathways, respectively. In addition, there are different precursor pools for mRNA and rRNA synthesis (small/non-expandable and large/ expandable) in Ehrlich ascites cells, ${ }^{20} \mathrm{HeLa}$ S3 cells, $^{21}$ regenerating rat liver, ${ }^{22}$ and rat hepatoma cells. ${ }^{23}$ The small pool is nucleolar (rRNA synthesis) and supplied mainly by de novo synthesis. ${ }^{212425}$ The large pool is under metabolic control in the sense that de novo synthesis is suppressed by exogenous supply. ${ }^{26}$

Precursor labelling problems can be circumvented by using $\left[{ }^{14} \mathrm{C}-\right.$ methyl $]$-methionine to label intracellular S-adenosylmethionine (SAM), the donor for methylation of rRNA during synthesis. ${ }^{27} 28$

MECHANICSMS OF CONTROL OF RIBOSOME SYNTHESIS

Several studies have noted that the time course of changes in cellular ribosome content usually comes before those of protein, often by a 
considerable margin. Ribosomal RNA is the most abundant species and accounts for the largest requirement for de novo and salvage of purines and pyrimidines.

It is synthesised in the nucleolus by RNA polymerase $\mathrm{I}$, which is separately regulated from the other nuclear polymerases. The primary transcript, $45 \mathrm{~S}$ pre-rRNA, is cleaved to $18 \mathrm{~S}$ and $28 \mathrm{~S}$ rRNA species, which exit the nucleus as mature $40 \mathrm{~S}$ and $60 \mathrm{~S}$ ribosomal subunits (Fig 2). A significant proportion of unmethylated 'spacer' region of pre-rRNA is degraded during processing. As such their nucleotides can enter the salvage pathway for subsequent reutilisation in RNA synthesis (see reviews by Warner ${ }^{29} 30$ ). In non-growing tissues, a further proportion (up to $50 \%$ ) of the $45 \mathrm{~S}$ pre-RNA is degraded completely, termed 'wastage'.

The supply of rRNA and ribosomal proteins is coordinated because if rRNA synthesis is inhibited, degradation of nucleolar rProteins increases $^{31} 32$ whereas if rProtein synthesis is inhibited, there is increased degradation of $45 \mathrm{~S}$ pre-rRNA. ${ }^{24} 3334$

This apparently expensive process ('wastage') that is loosely coupled to rProtein synthesis, gives exquisite control of cytoplasmic ribosome appearance rates. Warner ${ }^{29-31}$ has aptly called the inhibitory modulation of excess rRNA and rProtein concentrations (through degradation), 'fine tuning' of ribosome supply. The level of 'coarse tuning' would be supplied by gross coordinate changes in rProtein and rRNA synthesis in response to growth or nutritional depletion.

\section{RIBOSOME PRODUCTION AND GROWTH STIMULI}

Liver

The two phases of liver regeneration in the rat can be described as 'proliferative' (days 1-5) and 'post-proliferative' (days 6-12). Proliferative growth is accompanied by appearance of new cytoplasmic ribosomes (fivefold increase) and a twofold increase in rates of nucleolar $45 \mathrm{~S}$ pre-rRNA synthesis with a doubling of rates of $45 \mathrm{~S}$ rRNA elongation. ${ }^{35}$ In contrast, degradation of cytoplasmic ribosomes is unchanged. ${ }^{36-38}$ This implies that in the resting liver, nearly $60 \%$ of $45 \mathrm{~S}$ pre-rRNA was 'wasted' and because processing results in the loss of nearly $50 \%$ of $45 \mathrm{~S}$ pre-rRNA, of nucleotides incorporated into $45 \mathrm{~S}$ pre-rRNA, only $20 \%$ ever reaches the cytoplasm.

An acute phase response to turpentine injection increases cytokine production and the export of acute phase proteins by liver. This response is mediated by increased ribosome production and their transport from the nucleolus within five hours of treatment which comes before the activation of the acute phase protein response. ${ }^{39} 40$

\section{Kidney}

Unilateral nephrectomy causes compensatory hypetrophic growth of the contralateral kidney, which will reach about $75 \%$ of the weight of both kidneys within two weeks. Within 48 hours, however, rRNA content/cell increases by $40 \% .{ }^{41}$ Two mechanisms are responsible for this, an increase in the efficiency of processing of $45 \mathrm{~S}$ pre-rRNA ${ }^{4142}$ and an increase in rDNA transcription and $45 \mathrm{~S}$ pre-rRNA synthesis within a few hours of surgery. ${ }^{43}$

\section{Growing muscle - normal and rapid growth}

During 'catch up' growth of protein depleted animals, the number of ribosomes in skeletal muscle doubles, as does the efficiency of ribosome use in protein synthesis. ${ }^{44}$ Severe protein/energy malnutrition results in a coordinated loss of cellular ribosomes and cell muscle protein $^{45}$ whereas energy deficiency reduces efficiency of ribosome use in protein synthesis. ${ }^{46} 47$ There are thus two mechanisms for modulating muscle protein synthesis, through changes in the number of ribosomes and their efficiency of use. During accelerated growth, this relation is perturbed as was shown during weight induced hypertrophy of the anterior and posterior latissimus dorsi muscles of chicken. ${ }^{48}$ Although muscle protein increased steadily over 50 days, RNA concentrations doubled within three days. The important factor that mediated increased muscle protein synthesis was therefore the number of ribosomes, not their efficiency of use - as also occurs during hypertrophy of the heart after surgical aortic stenosis. ${ }^{49-51}$

\section{NORMAL/TRANSFORMED CELL LINES}

Normal cells are responsive to exogenous growth signals in a way not shared with transformed cell lines. This is especially true in relation to the amount of every cellular component a normal or tumour cell must accumulate, before passing into the replicative phases of the cell cycle.

A 'competence signal' initiates recruitment into the cell cycle, while a 'progression signal' is essential for effective expression of growth. ${ }^{52} 53$ Normal 3T3 cells do not enter the cell cycle until their ribosome content reaches a certain threshold, in contrast with transformed 3T6.54 Thus, during stimulated cell growth, ribosome content should double before recruitment. ${ }^{55} \mathrm{~A}$ proliferative signal for cells of the immune system must therefore be accompanied by increased ribosome synthesis before division and immunoglobulin synthesis can occur.

\section{RESTING AND GROWING CELLS IN CULTURE}

The growth stimulus to lymphocytes, provided by the mitogen phytohaemagglutinin (PHA) is mediated in large part by increased ribosome production (10 to 50 -fold), which comes before DNA replication and cell division. ${ }^{56}$ This model thus represents an extreme anabolic stress and as in hypertrophying kidney, the increase in ribosome production is achieved through the end of the 'wastage' of $45 \mathrm{~S}$ pre-rRNA in resting cells. As described, this mechanism permits rapid increases in ribosome production at the least energetic 
cost. De novo synthesis provides most of the nucleotide flux for increased RNA and DNA synthesis, as suggested by the limited ability of exogenous nucleobases and nucleosides (salvage pathway) to relieve inhibition of growth by limiting amounts of glutamine in the culture medium (de novo pathway). ${ }^{57}$

\section{RESPONSES OF PURINE, PYRIMIDINE, AND} RIBOSOME METABOLISM TO GROWTH STIMUL Where protein intake is adequate, de novo synthesis provides the main source of nucleotides for nucleic acid synthesis. Although it can be suppressed by dietary purine and pyrimidine supply, the degree to which this occurs depends on the tissue type. Liver and gut behave differently. In the liver dietary purines increase the activity of salvage and catabolism pathways simultaneously, while the gut, which has only a low capacity for de novo synthesis is dependent on the liver for the supply of nucleotides. Where protein intake is reduced, the salvage pathway assumes a greater importance as a means of recycling purines and pyrimidines released by nucleic acid catabolism. Lack of dietary purines and pyrimidines will switch on de novo synthesis in the gut, to a limited extent.

Within the cell itself, the split between do novo and salvage pathways differs for each species of RNA. Ribosomal RNA production seems to rely more heavily on de novo synthesis than does mRNA or tRNA synthesis. In this sense, an important component of protein synthesis (the ribosome) can be seen to be under the same general nutritional controls as protein synthesis itself, that is the dietary amino acid supply.

The importance of an adequate increase in cellular ribosome synthesis during enterocyte production and maturation can be inferred from the known effects of malnutrition on mucosal architecture and cell kinetics. This relation holds true for many other cell types and there is no reason to believe that the enterocyte is an exception. Its reliance on de novo pathways, and the low levels of these pathways, may make this cell type particularly sensitive to any limitation of purine and pyrimidine supply. This situation will occur in the malnourished patient, or one receiving nutrition support without added purines or pyrimidines.

Evidence for a positive role for purines and pyrimidines in clinical nutrition

Dietary supplementation with nucleotides, nucleosides or nucleobases can improve growth rates and nitrogen retention in young animals. 1058 Furthermore, four lines of evidence suggest that supplementation with dietary or parenteral nucleotides/nucleosides may be of clinical significance.

\section{INFECTION AND IMMUNE FUNCTION}

The ability of mice to survive intravenous injections of Candida albicans was shown to be con- siderably enhanced by the addition of yeast RNA or individual purines and pyrimidines to an otherwise nucleotide free diet. ${ }^{5960}$ As described above, this protective effect is dependent on the route of administration because oral nucleotide intake does not result in such avid uptake by the spleen. The most recent study has confirmed that intraperitoneal administration of nucleosides can reduce death, after Staphylococcus aureus innoculation, from 71 to $21 \%$ in mice. ${ }^{61}$ In addition, Kulkarni et al investigated the effects of nucleotide free diets in impairing fatal graft $v$ host reactions in irradiated mice. The mirror to these experiments was to determine the proliferative potential of transplanted lymphocytes in animals receiving nucleotide free and nucleotide supplemented diets. ${ }^{62}$ Surprisingly, nucleotide free diets were immunosuppressive in that mortality graft $v$ host reactions was significantly reduced. Conversely, nucleotide free diets reduced the responsiveness of lymphocytes to PHA, to a very noticeable extent. These results are similar to those seen in malnourished animals but should be considered with some care. Thus, lymphocyte responsiveness is a measurable aspect of the ability of a cell type to mount its appropriate response but its clinical significance is not clear. Although it has proved difficult to show clinically significant effects of the nutritional state on immune function, ${ }^{63}$ the finding that death rates were significantly reduced by nucleotide supplementation is highly suggestive.

\section{LIVER REGENERATION}

Using the $70 \%$ hepatectomy model in rats, supplementation of total parenteral nutrition regimens with nucleotides and nucleosides (as $10 \%$ of amino acid nitrogen) significantly increased post-operative nitrogen balance (became positive) and whole body protein turnover and synthesis. ${ }^{64} 65$ This treatment also reduced the extent of galactosamine induced liver injury, as judged by histological tests and circulating concentrations of the liver enzymes aspartate transaminase and alanine transaminase. ${ }^{11}$ These data suggest that repair and growth in an important organ of purine and pyrimidine biosynthesis can be improved by providing an external supply of preformed nucleotides and nucleoside.

\section{INTESTINAL REPAIR}

The effect of nucleotides present in white cells in milk on gut maturation has never been quite clear, but has interested paediatric gastroenterologists nevertheless. As a model of mucosal damage during infective diarrhoea, Nunez et al ${ }^{66}$ induced chronic diarrhoea in weaning rats by substituting the maltodextrins in the enteral diet with lactose. Nucleotide supplementation partially restored the biochemical atrophy of the small intestine at proximal and distal sites. There were significant increases in protein content and brush border saccharidases, although the changes were not large. Nucleoside supplementation 
increased the rate of maturation and growth in the young rat, as assessed by mass, RNA, DNA, and protein concentrations and activity of brush border enzymes. ${ }^{67}$

As argued above, a limitation in de novo synthesis may be relieved by input into the salvage pathway. If true, it would reflect an interesting phenomenon because less than $1 \%$ of the flux of glutamine seems to go into de novo synthesis. ${ }^{68}$ If there is a limitation then nucleotide and not glutamine supplementation should relieve any de novo limitation, which can be detected biologically. A recent study ${ }^{69}$ investigated the effect of total parenteral nutrition supplementation with nucleosides (see above $^{6465}$ ) or glutamine on reversal of total parenteral nutrition induced gut atrophy in the rat. Nucleosides alone, or in combination with glutamine significantly increased villus height, total and mucosal jejunal wet weight, protein and RNA and brush border maltase and sucrase. The effects of nucleosides were more potent than those of glutamine alone.

In conclusion, because the gut has a high rate of protein turnover and is uniquely dependent on salvage and exogenous supplies of purines and pyrimidines, limitation in supply may impair maintenance of the barrier function in the malnourished and stressed patient. Normal diets probably provide sufficient purines and pyrimidines to allow for any such limitation, indeed 'requirements' are probably quite modest given the tight metabolic control of purine synthesis and degradation and low utilisation of dietary sources. Total parenteral nutrition or enteral nutrition is unusual in that no purine/ pyrimidine intake is given.

The few, relevant studies cited above are certainly persuasive and can only serve to promote further studies. It may be particularly fruitful to take animal models of stress in which it is known that the gut (barrier function) or immune system, is affected.

1 Heinrich PC, Castell JV, Andus T. Interleukin-6 and the acute phase response. Biochem f 1990; 265: 621-36.

2 Petersson B, Wernerman J, Waller S-O, von der Decken A, Vinnars E. Elective abdominal surgery depresses muscle protein synthesis and increases subjective fatigue: effects lasting more than 30 days. Br f Surg 1990; 77: 796-800.

3 D'Mello JPF. Utilization of dietary purines and pyrimidines by non-ruminant animals. Proc Nutr Soc 1982; 41: 301-8.

4 Giesecke D, Tiemeyer W. Availability and metabolism of purines of single-cell proteins in monogastric animals. Proc Nutr Soc 1982; 41: 319-27.

5 Zollner N. Purine and pyrimidine metabolism. Proc Nutr Soc 1982; 41: 329-42.

$6 \mathrm{Wu}$ G, Greene LW. Glutamine and glucose metabolism in bovine blood lymphocytes. Comp Biochem Physiol B 1992, 103: 821-5.

7 Savaiano DA, Ho CY, Chu V, Clifford AJ. Metabolism of orally and intravenously administered purines in rats. f Nutr 1980; 110: 1793-804.

8 Schanker LS, Jeffrey JJ, Tocco DJ. Interaction of purines with the pyrimidine transport process of the small intestine. Biochem Pharmacol 1963; 12: 1047-53.

9 Scharrer E, Stubenhofer L, Tiemeyer W, Bindl C. Active pyrimidine absorption by chicken colon. Comp Biochem Physiol A 1984: 77: 85-8.

10 Griefe HA, Molnar S. 14C-tracerstudien zum nukleinsauren-stoffwechsel von jungratten, kuken und ferkeln. 1: Mitteilung. Untersuchungen zum purinestoffwechsel der jungratte. $Z$ Tierphysiol Tierernahr Futtermittelkd 1983; 50 79-91.

11 Ogoshi S, Iwasa M, Kitagawa S, Ohmori Y, Mizobuchi S, Iwasa $\mathrm{Y}$, et al. Effects of total parenteral nutrition with nucleoside and nucleotide mixture on D-galactosamineinduced liver in rats. F Parent Ent Nutr 1988; 12: 53-7.

12 Savaiano DA, Clifford AJ. Adenine, the precursor of nucleic acids in intestinal cells is unable to synthesise purines de novo. F Nutr 1981; 111: 1816-22.
13 Sonoda T, Tatibana M. Metabolic fate of pyrimidines and purines in dietary nucleic acids ingested by mice. Biochim purines in dietary nucleic acids
Biophys Acta 1978; 521: 55-66.

14 Leleiko NS, Bronstein AD, Munro HN. Effect of dietary purines on de novo synthesis of purine nucleotides in the small intestinal mucosa. Pediatr Res 1979; 13: 403.

15 Leleiko NS, Bronstein AD, Baliga BS, Munro HN. de novo purine nucleotide synthesis in the rat small and large intestine: effect of dietary protein and purines. $\mathcal{f}$ Pediat Gastroenterol Nutr 1983; 2: 313-9.

16 Grobner W, Zollner N. Der einfluss von nahrungs-purinen und pyrimidinen auf der pyrimidinensynthese des menschen (The effect of dietary purines and pyrimidines on human pyrimidine biosynthesis). Klin Wochenschr 1983; 61: 1191-7.

17 Loffler W, Grobner W. A study of dose-response relationships of allopurinol in the presence of low or high purine ships of allopurinol in the presence of low or
turnover. Klin Wochenschr 1988; 66: 153-9.

18 Gross CJ, Stiles JE, Savaiano DA. Effect of nutritional state and allopurinol on purine metabolism in the rat smal intestine. Biochim Biophys Acta 1988; 966: 168-75.

19 Ghiggeri GM, Ginevri F, Cercignani G, Oleggini R Garberi A, Candiano G, et al. Effect of dietary protein restriction on renal purines and purine-metabolizing enzymes in adriamycin nephrosis in rats: a mechanism for protection against acute proteinuria involving xanthine oxidase inhibition. Clin Sci 1990; 79: 647-56.

20 Genchev DD, Kermechiev MB, Hadjiolov AA. Free pyrimidine nucleotide pool of Ehrlich ascites-tumour pyrimis. Biochem $\mathcal{f} 1980 ; 188$ : 85-90.

21 Wiegers U, Kramer G, Klapproth K, Hilz H. Separate pyrimidine-nucleotide pools for messenger-RNA and ribosomal-RNA synthesis in HeLa S3 cells. Eur $\mathcal{F}$ Biochem 1976; 64: 535-40

22 Ove P, Adams RLP, Abrams R, Lieberman I. Liver uridine triphosphate after partial hepatectomy. Biochim Biophys Acta 1966; 123: 419-21.

23 Losman MJ, Harley EH. Evidence for compartmentation of uridine nucleotide pools in rat hepatoma cells. Biochim Biophys Acta 1978; 521: 762-9.

24 Grummt I, Smith VA, Grummt F. Amino acid starvation affects the initiation frequency of nucleolar RNA polymerase. Cell 1976; 7: 439-45.

25 Grummt I, Grummt F. Control of nucleolar RNA synthesis by the intracellular pool sizes of ATP and GTP. Cell 1976; 7: 447-53.

26 Goody HE, Ellem KAO. Nutritional effects on precursor uptake and compartmentalization of intracellular pools in relation to RNA synthesis. Biochim Biophys Acta 1975 383: 30-9.

27 Grimble GK, Millward DJ. The measurement of ribosoma ribonucleic acid synthesis in rat liver and skeletal muscle in vivo. Biochem Soc Trans 1977; 5: 913-6.

28 Grimble GK. RNA metabolism in skeletal muscle (Thesis). London: University of London, 1981.

29 Warner JR. The nucleolus and ribosome formation. In: Nomura M, Tissieres A, Lengyel P, eds. The ribosomes. New York: Cold Spring Habor Laboratory, 1974: 461-88.

30 Warner JR. The nucleolus and ribosome formation. Curr Opin Cell Biol 1990; 2: 521-7.

31 Warner JR. In the absence of ribosomal RNA synthesis, the ribosomal proteins of HeLa cells are synthesised normally and degraded rapidly. f Mol Biol 1977; 115: 315-33.

32 Tsurugi $K$, Ogata $K$. Degradation of newly synthesised ribosomal proteins and histones in regenerating rat live with and without treatment with a low dose of Actinomycin D. Eur f Biochem 1979; 101: 205-13.

33 Stoyanova BB, Hadjiolov AA. Alteration in the processing of rat-liver rRNA caused by cycloheximide inhibition of protein synthesis. Eur $\mathcal{F}$ Biochem 1979; 96: 357-62.

34 Karagyozov LK, Stoyanova BB, Hadjiolov AA. Effect of cycloheximide on the in vitro synthesis of ribosomal RNA in rat liver. Biochim Biophys Acta 1980; 607: RNA in

35 Dudov KP, Dabeva MD. Post-transcriptional regulation of ribosome formation in the nucleus of regenerating rat liver. Biochem f 1983; 210: 183-92.

36 Loeb JN, Yeung LL. Synthesis and degradation of ribosomal RNA in regenerating liver. $\mathcal{F}$ Exp Med 1975; 142: 575-87.

37 Nikolov EN, Dabeva MD. Turnover of ribosomal $28 \mathrm{~S}$ and $18 \mathrm{~S}$ rRNA during rat liver regeneration. Biosci Rep 1983 15: $1255-60$.

38 Nikolov EN, Dabeva MD, Nikolov TK. Turnover of ribosomes in regenerating rat liver. Int $\mathcal{F}$ Biochem 1983; 15: $1255-60$.

39 Aletti MG, Picolletti R, Bernelli-Zazzera A. Release of rRNA from liver nuclei during the early stages of the rRNA from liver nuclei during the early stages of the acute-ph $179-82$.

40 Piccoletti R, Aletti MG, Bernelli-Zazzera A. Inflammation associated events in liver nuclei during acute-phase reaction. Inflammation 1986; 10: 109-17.

41 Hill JM, Ab G, Malt RA. Ribonucleic acid labelling and nucleotide pools during compensatory renal hypertrophy. Biochem $\mathcal{F}$ 1974; 144: 447-53.

42 Hill JM. Ribosomal RNA metabolism during renal hypertrophy. Evidence of decreased degradation of newly synthesized ribosomal RNA. F Cell Biol 1975; 64: 260-5.

43 Ouellette AJ, Moonka R, Zelenetz AD, Malt RA. Regulation of ribosome synthesis during compensatory renal hypertrophy in mice. Am $\mathcal{f}$ Physiol 1987; 253: C506-13. 
44 Millward DJ, Garlick PJ, Stewart RJ, Nnanyelugo DO, Waterlow JC. Skeletal-muscle growth and protein turnover. Biochem ₹ 1975; 150: 235-43.

45 Spence CA, Hansen Smith FM. Comparison of the chemical and biochemical composition of thirteen muscles of the rat after dietary protein restriction. $\mathrm{Br} \mathcal{F}$ Nutr 1978; 39: 647-58.

46 Millward DJ, Garlick PJ, James WP, Nnanyelugo DO, Ryatt JS. Relationship between protein synthesis and RNA content in skeletal muscle. Nature (Lond) 1973; 241: 204-5.

47 Millward DJ, Nnanyelugo DO, Garlick PJ. The effect on muscle protein metabolism of refeeding protein-depleted. Proc Nutr Soc 1974; 33: 115-6A

48 Laurent GJ, Sparrow MP, Millward DJ. Turnover of muscle protein in the fowl. 2 . Changes in rates of protein synthesis and breakdown during hypertrophy of the anterior and posterior latissimus dorsi muscles. Biochem $\mathcal{f}$ 1978; 176: 407-17.

49 Mazzetti G, Ferrari S, Davilli P, Battini R, Corti A. Peptide chain initiation and analysis of in vitro translation chain initiation and analysis of in vitro translation products in rat heart undergoing

50 Morgan HE, Siehl D, Chua BH, Lautensack-Belser N. Faster protein and ribosome synthesis in hypertrophying heart. Basic Res Cardiol 1985; 80 (suppl 2): 115-8.

51 Ray A, Aumont MC, Ausseday J, Bercovici J, Rossi A, Swynghedauw B. Protein and $28 S$ ribosomal RNA fractional turnover rates in the rat heart after abdominal aortic stenosis. Cardiovasc Res 1987; 21: 587-92.

52 Mercer WE, Avignolo C, Galanti N, Rose KM, Hyland JK, Jacob ST, et al. Cellular DNA replication is independent of the synthesis or accumulation of ribosomal RNA. Exp Cell Res 1984; 150: 118-30.

53 Seuwen K, Steiner U, Adam G. Cellular content of ribosomal RNA in relation to the progression and competence signals governing proliferation of

54 Kleuzer B, Adam G. Interrelation between cellular rRNA content and regulation of the cell cycle of normal and transformed mouse cell lines. Cell Biol Int Rep 1985; 9: 985-92

55 Johnson LF, Abelson HT, Green H, Penman S. Changes in RNA in relation to growth of the fibroblast I: amounts of mRNA, rRNA and tRNA in resting and growing cells. Cell 1974; 1: 95-100.

56 Cooper HL. Studies on RNA metabolism during lymphocyte activation. Transplant Rev 1972; 11: 3-38.

57 Szondy Z, Newsholme EA. The effect of various concentrations of nucleobases, nucleosides or glutamine on the incorporation of $\left[{ }^{3} \mathrm{H}\right]$ thymidine into DNA in rat mesenteric-lymph-node lymphocytes stimulated by phytohaemagglutinin. Biochem $\mathcal{f} 1990 ; 270$ : 437-40.

58 Gyorgy P. The uniqueness of human milk: biochemical aspects. Am $\mathcal{f}$ Clin Nutr 1971; 24: 970-5.

59 Kulkarni AD, Fanslow WC, Rudolph FB, Van Buren CT. Effect of dietary nucleotides on bacterial infections. Parent Ent Nutr 1986; 10: 169-71.

60 Fanslow WC, Kulkarni AD, Van Buren CT, Rudolph FB. Effect of nucleotide restriction and supplementation on resistance to experimental murine candidiasis. $\mathcal{F}$ Parent Ent Nutr 1988; 12: 49-52.

61 Adjei AA, Takamine F, Yokoyama H, Shiokawa K, Matsumoto Y, Asato L, et al. The effects of oral RNA and intraperitoneal nucleoside-nucleotide administration on methicillin-resistant Staphylococcus aureus infection in mice. $\mathcal{F}$ Parent Ent Nutr 1993; 17: 148-52.

62 Kulkarni SS, Bhateley DC, Zander AR, Van Buren CT, Rudolph FB, Dicke KA, et al. Functional impairment of T-lymphocytes in mouse radiation chimeras by a -lymphocytes in mous Hematol 1984; 12: 694-9.

63 Christou N. Perioperative nutritional support: immunologic defects. F Parent Ent Nutr 1990; 14: 186-92S.

64 Ogoshi S, Iwasa M, Tamiya T. Effect of nucleotide and nucleoside mixture on rats given total parenteral nutrition after $70 \%$ hepatectomy. $\mathcal{F}$ Parent Ent Nutr 1985; 9: 339-42.

65 Ogoshi S, Iwasa M, Mizobuchi S, Iwasa Y, Martiz A, Tamiya T. Effect of nucleoside and nucleotide mixture on protein metabolism in rats given total parenteral nutrition after $70 \%$ hepatectomy. In: Tanaka T, Okada A eds. Nutritional support in organ failure. Amsterdam: Elsevier Science (Biomedical Division), 1990: 309-17.

66 Nunez MC, Ayudarte MV, Morales D, Suarez MD, Gil A. Effect of dietary nucleotides on intestinal repair in rats with experimental chronic diarrhoea. 7 Parent Ent Nutr with experimental

67 Uauy R, Stringel G, Thomas R, Quan R. Effect of dietary nucleosides on growth and maturation of the developing gut in the rat. F Pediatr Gastroenterol Nutr 1990; 10: 497-503.

68 Newsholme EA, Carrie A-L. Quantitive aspects of glucose and glutarine metabolism by intestinal cells. Gut 1994; 35 (suppl 1); S13-7.

69 Iijima S, Tsujinaka T, Kido Y, Hayashida Y, Ishida H, Homma $T$, et al. Intravenous administration of nucleosides and a nucleotide mixture diminishes intestinal mucosal atrophy induced by total parenteral nutrition. mucosal atrophy induced by total 